\title{
A Theology of Everything
}

\author{
GEORGE V. COYNE S.J. \\ Le Moyne College, 1419 Salt Springs Road, Syracuse, New York 13214, USA. \\ E-mail: coynegv@lemoyne.edu
}

\begin{abstract}
The rise of natural theology in the seventeenth century did not originate in theology, but in science. It was not started by theologians trying from above to impress a religious perspective on science. On the contrary, the natural theology of the century of the Enlightenment began as a grass-roots movement among believing scientists who were convinced both that God's existence could be proved and some of His attributes described from below, that is, on the basis of the expanding world of scientific knowledge. Essentially they were arguing for the existence of a Deity whose direct intervention would explain the gaps in the scientific discourse. But this manner of reasoning made natural theology extremely vulnerable. It would clearly lose its power at the moment when the scientific discourse itself became sufficiently advanced to close the gaps by its own force.
\end{abstract}

\section{Introduction}

The natural theology of the Enlightenment was a formidable success; it drew every field of natural science into its orbit, and engaged scientists of all descriptions. It even survived into the nineteenth century when it found its last, impressive monument in the Bridgewater Treatises, a series of eight monographs by scientists selected by the president of the Royal Society of London and the Archbishop of Canterbury and endowed by the Earl of Bridgewater, Francis Henry (1756-1829). The testament of this industrial baron stipulated that these books should be:

On the Power, Wisdom and Goodness of God as manifested in the Creation; illustrating such work by all reasonable arguments, as for instance the variety and formation of God's creatures in the animal, vegetable and mineral kingdoms; the effect of digestion and thereby of conversion; the construction of the hand of man and an infinite variety of other arguments; as also by discoveries ancient and modern, in arts, sciences and the whole extent of literature. ${ }^{1}$

This stipulation was an admirable summary of the previous tradition of natural theology. However, even if some of the Bridgewater Treatises came to play a significant role in the debate on science and theology in the nineteenth century, their publication was a kind of rearguard action, destined to bolster the dwindling vitality of a movement that had run into serious trouble because of the development of the very sciences in which it had originated. 


\section{The Success of Classical Mechanics}

Before we discuss the imminent 'serious trouble' it would be helpful to discuss a few exemplary cases of the Enlightenment scientific rationalism. Johannes Kepler and Galileo Galilei provided a completely new point of departure for the science of mechanics. Kepler's discovery of the three fundamental laws of planetary motion revealed for the first time in history how a mechanical system actually behaved. Similarly, Galileo had shown how another phenomenon of motion, the freefall of bodies towards the Earth, would behave in the ideal case where the resistance of the air could be disregarded in the first approximation as merely a slightly disturbing influence to be dealt with in a more detailed version of the theory. Soon after, further reflections on the influence of friction led to the concept of force-free or inertial motion with constant velocity along a straight line, as expressed in the Principle of Inertia.

This enabled Renee Descartes qualitatively to analyze the circular motion of a body around a fixed center under the influence of an inertial drive in the direction of the tangent and a centripetal force directed towards the center. And in 1657 Huygens succeeded in deriving a precise expression for this force by an ingenious application of Galileo's law of free fall to an infinitesimal part of the circular movement. This led again to a theory of the pendulum and its application as a time keeper of a new type of mechanical clock. It was clear that mechanics was now rapidly establishing itself at the cutting edge of natural philosophy.

The climax to all of this came in 1687 when Isaac Newton published the Principia Mathematica Philosophiae Naturalis in which all the durable results of the century were presented in a great synthetical exposition, which has ever since maintained its position as the basic work of what is now called Classical Mechanics. At the bottom of this great work was the hypothesis that any two bodies in the universe attract each other with a force that varies as the inverse square of their distances. Newton, however, offered no explanation of the 'cause' of this universal gravitation.

Newton's work made a strong impact on eighteenth-century minds. Voltaire hailed Newton as the great rationalist in whom human reason had defeated the intellectual darkness of all previous ages, a picture that also satisfied the positivistic philosophers of science in the nineteenth century. This view was disturbed, however, when it transpired that Newton had spent much of his time on abstruse subjects that were deemed unworthy of the attention of a great scientist, such as ancient history, alchemy, and theology. ${ }^{2}$

\section{Newton's Theology}

In the General Scholium, added to the second edition of the Principia (1713), Newton disclosed that the very foundation of his ideas about the physical world was closely connected with his concept of God. As early as 1660, in discussing space, he suggests that space is not a 'part' of God's essential nature, but a secondary 'effect' or 'emanation' of God's ubiquity and omnipotence. ${ }^{3}$ However, almost 20 years later he tried, in the first edition of the Principia to translate his view of space into a non-theological language by describing 'absolute space' as something which 'in its own nature, without relation to anything external, remains always similar and immovable,' contrary to 'relative space' 
which is some 'movable dimension or measure of the absolute spaces; which our senses determine by its position to bodies. ${ }^{4}$ Space is 'absolute' because it is independent of what it contains, and the traditional connection between matter and space is dissolved.

That Newton did not here discuss the theological origin of this vision of space had serious consequences for the understanding of the Principia as the seminal work of classical physics. 'Absolute space' seemed here to appear out of the blue and as time went on it became increasingly clear that it was impossible to derive it from physical concepts related to observable phenomena. Consequently, it was treated by positivistic philosophers of science as an illegitimate or foreign element smuggled into a discourse in which all non-physical notions ought to be absent.

Newton chose to explain his ideas on God and nature in the General Scholium added to the second edition of the Principia in 1713. Newton here changes his vocabulary: space is no longer an 'emanation' from God. Nevertheless, it is 'constituted' by God as a necessary consequence of His existence everywhere. So, although the words are different, the basic concept seems to be unchanged. Newton's absolute space is still derived from his notion of God.

The principal question was whether the Newtonian hypothesis of a universal gravitation was able to explain all the known features of the universe in general and the Solar System in particular. In the Principia, Newton had demonstrated that the law of gravitation led to Kepler's laws, by which the motion of any planet in its elliptical orbit around the Sun is sufficiently described, just as such phenomena as the motion of the tides and the precession of the equinoxes had found a mechanical explanation. But this was only a partial success of the new celestial mechanics for there were still a number of striking features of the Solar system that defied theoretical explanation. Thus, in his first letter to the classical scholar Richard Bentley, ${ }^{5}$ Newton underlined the remarkable facts that all the planets move in the same direction around the Sun and that the moons of the Earth, Jupiter and Saturn move in the same direction around their respective planets. There is no known reason for this 'harmony' or agreement since the theory prescribes no definite direction of the motion of bodies in their orbits.

Similarly there is no known reason for the fact that both the planets and their moons all move in almost the same plane; that this is not due to any necessity in nature appears from the observational fact that many comets in the solar system move in orbits that are strongly inclined to this plane. The lack of theoretical reasons for such striking agreements, and his refusal to regard them as mere coincidences, made Newton conclude that 'the motions which the planets now have could not spring from any natural cause alone but were imprest by an intelligent Agent, ${ }^{6}$ an agent whom Newton, as it were, salutes in terms of professional admiration, for 'to adjust all these things together in so great a variety of bodies argues that cause to be not blind and fortuitous, but very well skilled in Mechanics and Geometry., 7

Another train of argument by Newton starts with considerations of the initial state of the Universe and its subsequent development. Assuming that in the beginning all matter was evenly scattered throughout a finite part of space one must conclude that gravitational attraction would make all the particles collapse into one single, spherical body in the middle. This would explain the existence of the sun, but not the fact that there is a 
multitude of fixed stars of much the same kind. On the other hand, if there was an initial diffusion of matter throughout an infinite space there might be formed an infinite number of condensed bodies; but it would not explain why some of these should be luminous like the Sun while others are dark like the planets.

So with respect to the actual state of the universe Newton is once again 'forced to ascribe it to the counsel of a voluntary Agent; for Why there is one body in our Systeme qualified to give light and heat to all the rest I know no reason but because the author of the Systeme thought it convenient, and why there is but one body of this kind I know no reason but because one was sufficient to ward and enlighten all the rest. ${ }^{8}$

\section{Enter the Naturalists}

While Newton was exploring the theological implications of his new theory of the physical universe, other scientists pursued apologist purposes in a somewhat different manner. Among them were a number of naturalists who would approach the Book of Nature in another way than a mathematical physicist. The naturalists were fascinated by the numerous marvels of the living world. In this field they had become acquainted with a great range of previously unknown phenomena. These were described in books and papers that often gave vent to feelings of awe in front of a universe possessed of so many minute biological details.

And from this there was only a short step to considering The Wisdom of God Manifested in the Works of Creation, to quote the title of a seminal work by the zoologist John Ray (1691). ${ }^{9}$ The general argument of this and numerous other works of the same kind was that there were many biological phenomena that did not explain themselves in a natural way, but pointed to a wise and good Creator as their necessary origin. Here we can discern two different strands of reasoning. The first strand concentrated on the significant way in which living beings were adapted to their different environments, and their organs to their specific functions, while the second was more concerned with the complexity of all the phenomena of life. In his Disquisition about the Final Causes of Natural Things (1688) Robert Boyle maintained that

there are some things in nature so curiously contrived, and so exquisitely fitted for certain operations and uses, that it seems little less than blindness in him, that acknowledges, with the Cartesians, a most wise author of things, not to conclude, that, though they may have been designed for other, and perhaps higher uses, yet they were designed for this use. $^{10}$

This exemplified how in many ways, among which were Boyle's descriptions of the animal or human eye, this became a classic instance that was repeated again and again:

He that sees the admirable fabric of the coats, humors, and muscles of the eye, and how excellently all the parts are adapted to the making up of an organ of vision, can scarce forbear to believe, that the author of nature intended it should serve the animal, to which it belongs, to see with. ${ }^{11}$

This manner of arguing will be embodied later on in William Paley's Natural Theology. ${ }^{12}$ Paley had moved a long way from the early versions of natural theology and classical 
mechanics, for the obvious reason that the physical nature of the individual celestial bodies was not known in any detail.

This had not deterred Newton from finding evidence of design in the properties of the planetary system, even if he knew very little about its individual components. There may have been several reasons for this shift of emphasis from mere design in mechanical systems to purposeful design in living systems. On the one hand the scientific development of the Newtonian system of the world became increasingly dependent upon new and highly advanced mathematical methods, which only a few specialists would be able to master. This contrasted with the situation within the life sciences that had entered on a course of apparently endless discoveries that were in most cases immediately understandable to the lay mind. On the other hand, the change may also have had something to do with teleological reasoning as such.

Newton had wondered why the planets all go the same way around the Sun, and seen this inexplicable fact as a result of design; but it was difficult to find any purpose behind it since no conceivable benefit followed from this particular behavior. But in biology the situation was different. Here it was not at all difficult to realize that, for instance, the eye had been structured in such a way that it could serve the obvious purpose of seeing. In other words, while the design in nature appeared in Newtonian astronomy in a negative way as a mere absence of chance, it was positively disclosed in biology as a presence of purpose. Another matter is that by shifting their attention from physics to biology the champions of Natural Theology moved into a dangerous area in which their ideas were more vulnerable to the attacks to which they would be exposed as a consequence of the very development of science.

\section{Summary}

It is impossible to deny that natural theology was a truly remarkable movement which demands our attention as the last historical instance of a major interaction between science and theology. In later times, nature has been praised by poets for its captivating beauty or by philosophers for its challenging variety of phenomena demanding explanation. But never since has it been extolled by an almost unanimous chorus of scientists as hailing from the finger of God and, therefore, replete with evidence of his wisdom and power. Astronomers, physicists and naturalists here joined ranks with Job and the Psalmist in recognizing God as the ultimate ground of everything in heaven and upon earth. For this was perhaps the most notable mark of the movement: it did not originate in theology, but in science. It was not started by theologians trying from above to impress a religious perspective on science. It began as a grass root-movement among believing scientists who were convinced both that God's existence could be proved and some of His attributes described from below, that is, on the basis of the expanding world of scientific knowledge. This also convinced them that they had nothing to fear from the indubitable progress of science; for beyond the receding frontier between the known and the unknown there was no dark and dangerous abyss in which the religious mind might get lost, but just another territory to be surveyed in the search for new evidence of the Creator. 
The birth of modern science occurred during the period of the Enlightenment in Western Europe where Christian belief was dominant. The end result, to my mind, is that in that surge of scientific reasoning, most scientists, who were religious believers, were unreasonable in their approach to religious belief, since they sought to found their religious belief on purely rational grounds. This created among some people, and continuing today among many, an unnecessary, to my mind, rift between science and religious belief. While philosophical and theological reasoning may serve as a prolegomena to religious faith and while faith does not of itself contradict any rational discourse, true religious faith is, for use of a better word, transcendent. It goes beyond the rational.

Atheism is an exercise in faith. I know of no rational proof that God does not exist. While it may defy logic to require a proof that something or someone does not exist, the long and profound history of religions throughout humanity's time on this earth should be approached more reasonably than happens among most modern atheists. To what extent this is an inheritance from the age of the birth of modern science might stimulate our discussions.

\section{Acknowledgements}

I must express a debt of gratitude to Olaf Pedersen for many discussions concerning the topic of this paper and especially that I was privileged after his death to edit and publish his manuscript: The Two Books: Historical Notes on Some Interactions Between Natural Science and Theology (Notre Dame, IN: University of Notre Dame Press, 2007) 424 pp.

\section{References}

1. Quoted in C. E. Raven (1953) Natural Religion and Christian Theology (Cambridge) I, 210 where the titles of the eight Bridgewater Treatises are also listed.

2. See Opticks, Query 31, in E. T. Whittaker (ed.) (1931) (London) p. 389.

3. See the fundamental studies by J. E. McGuire (1978) Newton on place, time and God: an unpublished source. British Journal for the History of Science, 11, pp. 114-129; and J. E. McGuire (1978) Existence, actuality and necessity: Newton on space and time. Annals of Science, 35, pp. 463-508.

4. Isaac Newton (1729) Principia, Scholium to the Definitiones, 5. In The Mathematical Principles of Natural Philosophy, trans. A. Motte (London:).

5. Most of Bentley's letters are lost, but four letters from Newton have survived. They were first published as Four Letters from Sir Isaac Newton to Doctor Bentley containing some Arguments in Proof of a Deity (London, 1756). The most recent edition is in H. W. Turnbull (1961) The Correspondence of Isaac Newton (Cambridge) III, pp. 233-256. The first letter is from December 1692. Similarly, Newton later told his relative John Conduitt that he had written the Principia 'not with a design of bidding defiance to the Creator but to enforce and demonstrate the power and superintendency of the supreme being' (King's College Keynes MS 130 [6]).

6. H. W. Turnbull (1961) The Correspondence of Isaac Newton (Cambridge) III, p. 234.

7. H. W. Turnbull (1961) The Correspondence of Isaac Newton (Cambridge) p. 235.

8. H. W. Turnbull (1961) The Correspondence of Isaac Newton (Cambridge), 234.

9. J. Ray (1691) The Wisdom of God Manifested in the Works of Creation (London).

10. The works of the Honourable Robert Boyle in Five Volumes to which is Prefixed the Life of the Author (London: 1744) IV, p. 579. 
11. It was developed in particularly great detail in the Boyle's Lectures given in 1711-1712 by William Derham (1657-1735) and published in W. Derham (1713) Physico-Theology: or, a Demonstration of the Being and Attributes of God, from His Works of Creation, 7th edn, 1727 (London) Book IV, Ch. II, On Eye.

12. W. Paley (1802) Natural Theology or the Evidence of the Existence of the Attributes of the Deity (London:). By 1820 the book had gone through 20 editions.

\begin{abstract}
About the Author
George V. Coyne holds the McDevitt Chair of Religious Philosophy at Le Moyne College at Syracuse, New York, USA. He is Director Emeritus of the Vatican Observatory where he served as Director from 1978 to 2006 and as President of the Vatican Observatory Foundation from its founding in 1987 until 2011. He is a member of the International Astronomical Union, the American Astronomical Society, the Astronomical Society of the Pacific, the American Physical Society and the Optical Society of America. His main areas of research have been on mass-exchanging binary stars and protoplanetary disks around young stars. Parallel to his scientific research he has developed an interest in the history and philosophy of science and in the relationship between science and religion. He served as the head of the section on epistemology and science of the Galileo Commission, constituted by John Paul II in 1981. He has lectured widely on the results of that Commission.
\end{abstract}

